\title{
Finite Element Modeling as Three Dimensional of Effect of Cutting Speed in Turning Process
}

\author{
Kadir Gok ${ }^{*}$ \\ Dumlupinar University, Department of Machinery and Metal Technology
}

Arif Gok

Amasya University, Technology Faculty, Mechanical Engineering Department

\section{M.Burak Bilgin}

Amasya University, Technology Faculty, Mechanical Engineering Department

Article history This paper present a finite element model as 3D effects to

\section{Received:}

25.10.2014

Received in revised form: 27.12.2014

\section{Accepted:}

01.12 .2014

Key words: metal cutting, finite element analysis, cutting process. machining of cutting speed in turning proces. The P20 steel and tungsten carbide (WC) type material were selected for the workpiece and cutting tool, respectively. During the cutting process, the cutting speeds were selected as 100, 200, 300, 400 and 500. However, some parameters such as feed rate, and depth of cut were selected as constant. DEFORM-3D software was used for simulating the turning processes. It was researched effects on the temperature, cutting force, and tool stress and chip shape of cutting speed. As a result, the temperature on the cutting tool increases with increasing cutting speed. Variation in the normal and shear stresses occurring on the rake face of cutting tool is similar to stress distribution of Zorev. While continuous chip consists of in the low cutting speeds, consists a manner disconnection of chip in the high cutting speeds due to the thermal softening.

\footnotetext{
* Correspondence: kadirgok67@ hotmail.com r
} 


\section{Introduction}

Metal cutting is widely used in manufacturing with chip. Because provide to a good face quality both cutting tool selection and appropriate cutting parameters selection are very important in metal cutting. The Today, metal cutting event has been examined with FEM. In finite element method, the solution zone is composed of adjacent sub parts which are called finite element. It can be assumed that these sub parts are held together by nuts and screws. It is also assumed that when the bonding is removed, the sub parts are separated [1].

During the metal cutting, examine such as states cutting tool stresses, cutting forces, cutting tool wear, between cutting tool and workpiece temperature are both difficult and cost. FEM can be predicted all these states, so by selecting correct cutting parameters and appropriate material can provided a good face quality and the longer cutting tool wear. Many researchers studied on finite element method for metal cutting. Jaharah et al [2] presented the application of Finite element method (FEM) in simulating the effect of cutting tool geometries on the effective stress and temperature increased in turning AISI 1045. Dechjarern [3] investigated the effect of tool rake angle on cutting performance. Yanda et al [4] studied to find the optimum combination of tool geometry in machining processes which can minimize the tool wear using FEM. Bareggi et al [5] a supersonic nozzle has been used to generate a high velocity air jet to provide cooling at the tool-chip interface during metal cutting. Ucun and Aslantas [6] a series of studies were carried out to understand the effect of the number of coating layer and coating type on the forces, temperatures, shear angle, and tool stress. Patrascu and Carutasu [7] presented a FEM model for 3D simulation of turning process. Zhou et al. [8] presented a study of the effect of chamfer angle on tool wear of PCBN cutting tool.

In this study, it was researched effects on the cutting force, temperature, tool stress and chip shape of cutting speed. The P20 steel and tungsten carbide (WC) type material were selected for the workpiece and cutting tool, respectively. However cutting speeds were selected as change, other parameters such as feed rate, and depth of cut were selected as constant.

\section{Three Dimensional Modelling Using The Finite Element Method}

Deform software was used to simulate turning process under different cutting speed. This software has the capability to model the tool as an elastic object so that stress distributions in the tool can be predicted [9].

For simulation of turning process were selected P20 steel as workpiece and WC cutting tool. Cutting tools have not any rake and clearance angles. During the turning process, the cutting speeds were selected as change, while some parameters such as feed rate, and depth of cut were selected as constant. Code with CNMA 432 was selected as cutting type in these cutting simulations. Figure 1 shows CNMA 432 carbide insert. Cutting parameters and mechanic properties for WC cutting tool are seen Tab. 1. Variation with respect to temperature of elasticity modulus thermal expansion, thermal conductivity and heat capacity of P20 material was given in Tab. 2, Tab. 3, Tab. 4 and Tab. 5, respectively. 




Figure 1: CNMA 432 carbide insert.

Table 1: Properties of material and cutting parameters used in the simulations.

\begin{tabular}{c|c}
\hline Cutting Parameters & Values \\
\hline 3/10/2004 & HS_129 \\
\hline Workpiece Material & P20 (Machining) \\
\hline Cutting Material & WC (Tungsten Carbide) \\
\hline Insert Type & CNMA 432 \\
\hline Cutting Tool Tip Radius (mm) & 0.8 \\
\hline Rake Angle & $0^{\circ}$ \\
\hline Clearance Angle & $0^{\circ}$ \\
\hline Cutting Speed $(\mathrm{m} / \mathrm{min})$. & $100-200-300-400-500$ \\
\hline Depth of Cut $(\mathrm{mm})$ & 0.5 \\
\hline Feed Rate $(\mathrm{mm} / \mathrm{rev})$. & 0.3 \\
\hline Temparature $\left({ }^{\circ} \mathrm{C}\right)$ & 20 \\
\hline Heat Transfer Coefficient & 45 \\
\hline (W/mK) & $30 \mathrm{~mm}$ \\
\hline Cutting Length & 0.6 \\
\hline Friction Coefficient & 650279 \\
\hline Cutting Tool Material & 0.25 \\
\hline Young Modulus $(\mathrm{Mpa})$ & $4.986 \mathrm{e}-06$ \\
\hline Poisson Ratio & 58.9888 \\
\hline Thermal Expansion $\left(10-6 /{ }^{\circ} \mathrm{C}\right)$ & 15.0018 \\
\hline Thermal Conductivity $\left(\mathrm{W} / \mathrm{m}{ }^{\circ} \mathrm{C}\right)$ & \\
\hline Heat Capacity $\left(\mathrm{N} / \mathrm{mm} 2{ }^{\circ} \mathrm{C}\right)$ & Tungsten Carbide) \\
\hline
\end{tabular}

Table 2: Variation with temperature of elasticity modulus of P20 material

\begin{tabular}{c|c}
\hline Temperature $\left({ }^{\circ} \mathrm{C}\right)$ & Young Modulus $(\mathrm{MPa})$ \\
\hline 21.111 & $1.17 \mathrm{e}-05$ \\
\hline 14.888 & $1,21 \mathrm{E}-02$ \\
\hline 260 & $1,22 \mathrm{E}-02$ \\
\hline 34.333 & $1,24 \mathrm{E}-02$ \\
\hline 42.666 & $1,30 \mathrm{E}-02$ \\
\hline 48.222 & $1,31 \mathrm{E}-02$ \\
\hline 53.777 & $1.35 \mathrm{e}-05$ \\
\hline 64.888 & $1,39 \mathrm{E}-02$ \\
\hline 13.711 & $1.17 \mathrm{e}-05$ \\
\hline
\end{tabular}


Table 3: Variation with temperature of thermal expansion of P20 material

\begin{tabular}{c|c}
\hline Temperature $\left({ }^{\circ} \mathrm{C}\right)$ & Thermal Expansion $\left(10-6 /{ }^{\circ} \mathrm{C}\right)$ \\
\hline 21.111 & $1.17 \mathrm{e}-05$ \\
\hline 93.333 & $1,21 \mathrm{E}-02$ \\
\hline 20.444 & $1,22 \mathrm{E}-02$ \\
\hline 31.555 & $1,24 \mathrm{E}-02$ \\
\hline 42.666 & $1,30 \mathrm{E}-02$ \\
\hline 48.222 & $1,31 \mathrm{E}-02$ \\
\hline 81.555 & $1.35 \mathrm{e}-05$ \\
\hline 13.711 & $1,39 \mathrm{E}-02$ \\
\hline
\end{tabular}

Table 4: Variation with temperature of heat capacity of P20 material

\begin{tabular}{c|c}
\hline Temperature $\left({ }^{\circ} \mathrm{C}\right)$ & Thermal Conductivity $\left(\mathrm{W} / \mathrm{m}^{\circ} \mathrm{C}\right)$ \\
\hline 14.888 & 24.574 .927 \\
\hline 21.555 & 24.574 .927 \\
\hline 34.888 & 2.440 .297 \\
\hline 47.666 & 24.231 .012 \\
\hline 60.444 & 24.746 .884 \\
\hline 64.888 & 24.746 .884 \\
\hline 71.377 & 24.746 .884 \\
\hline
\end{tabular}

Workpiece was modeled as plastic while tool as rigid. Firstly, generated surface mesh. Surface mesh generated with 6730 polygons and 3365 points. After generated solid mesh. Solid mesh generated with 28462 elements and 6600 nodes. In the Figure 2. has been show that mesh structure of workpiece and cutting tool. Metal cutting process is occurred in the high temperature and high strain velocies. Many material models are used for numeric solution in the metal cutting processes. These models were Oxley, Johnson-Cook, Zerilli-Armstrong, NortonHoff Law.

Nowadays, JC model is commonly used as flow stress model of work material in modeling machining operations due to its accuracy and simplicity [10]. JohnsonCook model is defined better than other material models material behaviour in the high temperature and high strain velocies. Coefficients in this model can be provided with "Split Hopkinson Pressure Bar" (SHPB) test. It is shown that flow stress flow stress curve in Figure 4. for P20 material. Coefficients; A, Yield stress, B, strain factor, n, strain hardness constant, unit plastic strain, plastic strain velocity, referans plastic strain velocity, $\mathrm{C}$, constant based on strain velocity, $\mathrm{Tr}$, room temperature, Tm, melting temperature of workpiece.

Metal cutting simulation is performed at ambient temperature assuming the initial temperature is equal to $20^{\circ} \mathrm{C}$. The heat losses to the environment from the free surface of the workpiece material are determined by the heat flux.

$$
\mathrm{Q}=\mathrm{h}\left(\mathrm{T}-\mathrm{T}_{0}\right)
$$

where $\mathrm{h}=45 \mathrm{~kW} / \mathrm{m} 2^{\circ} \mathrm{C}$ is the heat transfer coefficient of the work material. $\mathrm{T}$ and $\mathrm{T}_{0}$ are the temperature of the work material and ambient temperature, respectively. In the cutting simulation, tool-chip friction was modeled with Shear-type behaviors. 
In this model, the assumption is made that consist of contact friction-shear stress along contact length between tool-chip.

$\sigma=\mathrm{mk}$

(2) where, $\sigma$ is the friction stress, $\mathrm{m}$ is the friction factor and $\mathrm{k}$ is the shear-yield stress of workpiece material. According to this theory, friction stress depends with friction factor to shear-yield stress value of workpiece. It was selected as $\mathrm{m}=0.6$.

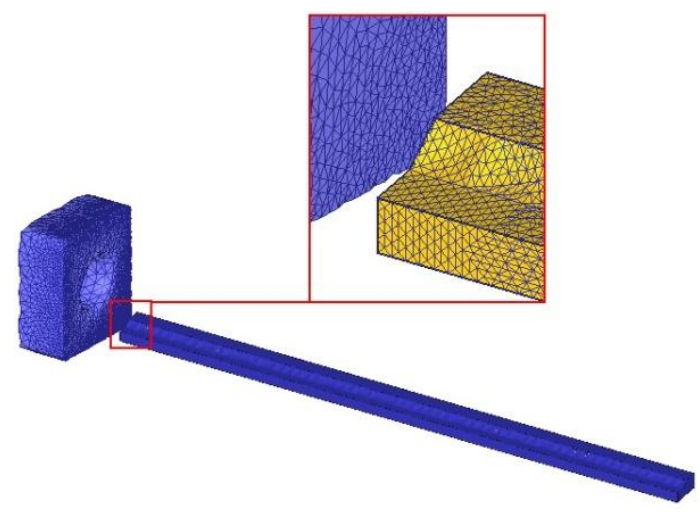

Figure 2: Mesh structure of cutting tool and workpiece, b) boundary conditions.

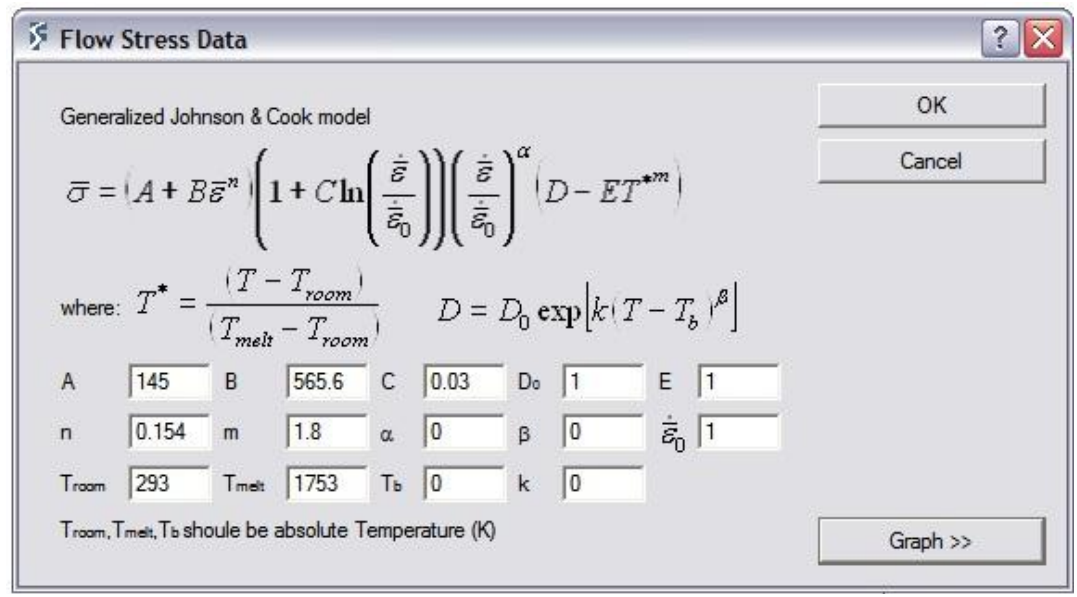

Figure 3: Flow Stress Data dialogue window.

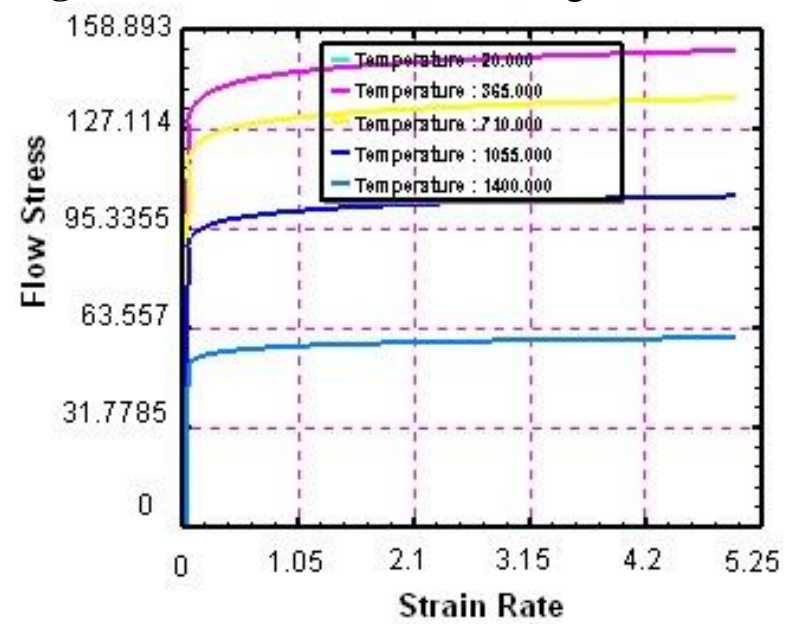

Figure 4: Flow Stress - Strain Rate 


\section{Results}

\subsection{Effect to Cutting Tool Temperature of Cutting Speed}

In the turning simulation process of different cutting speeds, temperature distribution which occurred on the cutting tool has been determined as three dimensional with Machining-3D module in DEFORM (Scientific Forming Technologies Corporation) software. Temperature distributions have been seen in Figure 5.

It can be seen that temperature increases with increasing cutting speed at the some study in the literature [11]; [12]. Strain rate in the first deformation zone will also increase with increasing cutting speed. Increasing starin rate will cause high heat formation during cutting, so temperature will also increase [13]. It can be seen that temperature increases with increasing of cutting speed as graphically in the Figure 6. In the Figure 7, temperature variation is seen occured seven different points on the rake face of cutting tool in the during 0.009 second cutting process. The maximum temperature between these points was occurred in the region which around P3 point and temperature of this region increases as variable with cutting times. Although P1 and P2 points are closer to the tool tip, their temperature values are less than $\mathrm{P} 3$ point. On the other hand, temperature values show a less away from the $\mathrm{P} 3$ point on the rake surface of cutting tool. As the highest temperature occurs in the region around P3 point, there is possibility of a crater wear in this region.

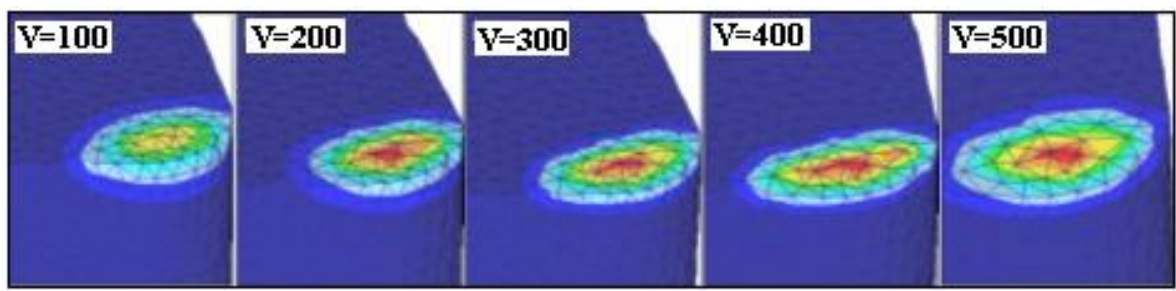

Figure 5: Temperature distributions which occurred on the cutting tool in the different cutting speeds.

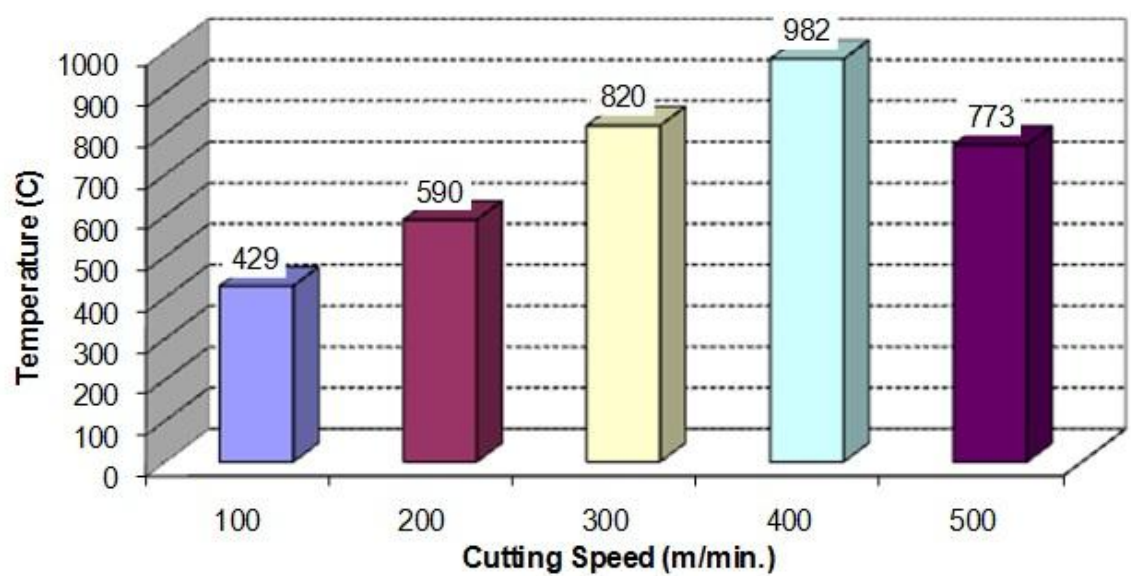

Figure 6: View as graphical of temperature values which occurred on the cutting tool 


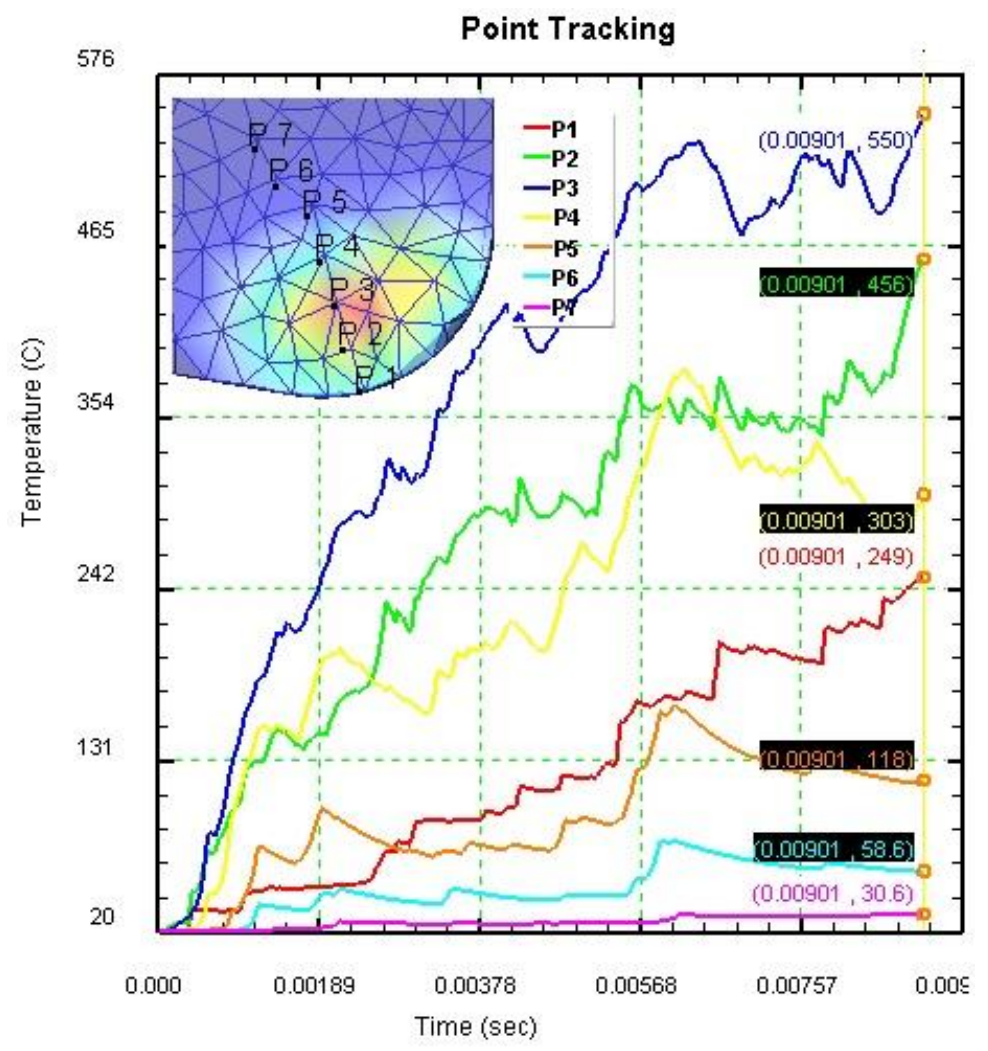

Figure 7: Temperature distributions at the different points of cutting tool.

\subsection{Effect to Cutting Force of Cutting Speed}

There are many factors in cutting process. These factors may have showed as cutting tool type, workpiece material and cutting parameters. Occured features in tool-chip interface during a cutting process are shown in Figure 8. Tangential Force $(\mathrm{Ft})$ : This force shows resistance to workpiece which turning in itself, Feed Force (Ff): This force shows resistance to feed of cutting tool in paralel direction to workpiece, Radial Force (Fr): This force is radial direction of workpiece center.

To determine average forces occurred on the cutting tool must add a new operation.
Firstly, generated surface mesh. Surface mesh generated with 6730 polygons and 3365 points. After generated solid mesh. Solid mesh generated with 28462 elements and 6600 nodes. Figure 9. has been show that mesh structure of workpiece and cutting tool. Immediately, interpolated force from workpiece to cutting tool. Cutting forces, which occured under the different cutting speed, have seen in Figure 10. With increasing of cutting speed has been seen a reduce in the cutting forces. This state is about with high temperature occurred in the tool-chip interface in the high cutting speeds. Temperature causes thermal softening high temperature region on the workpiece. 


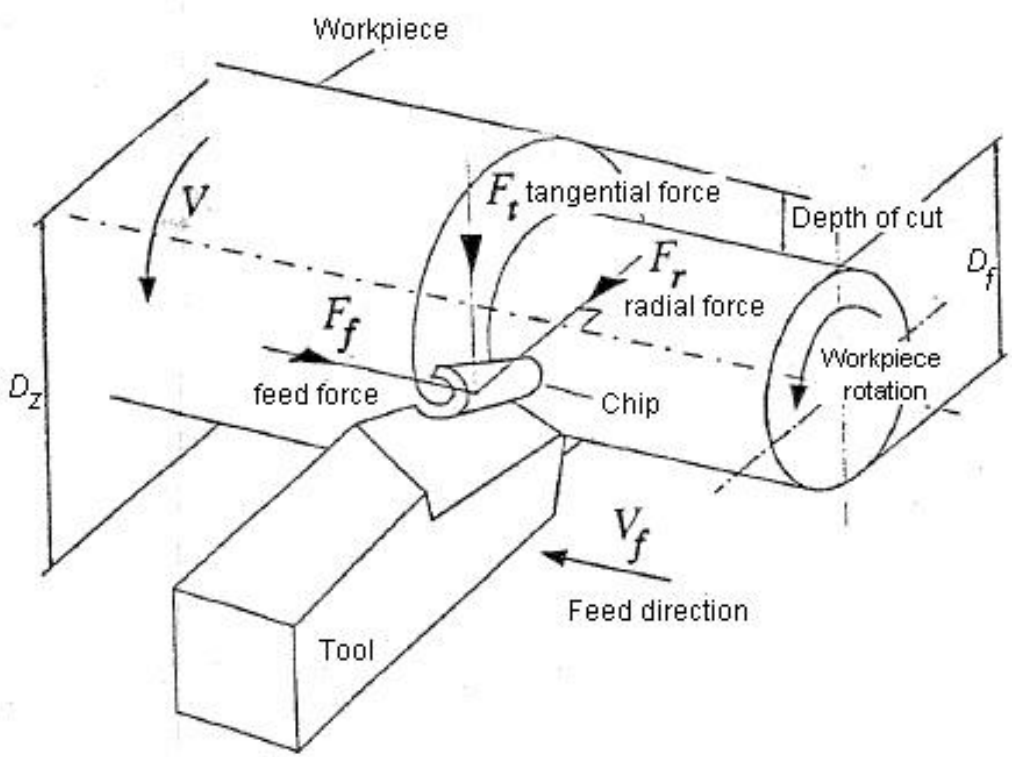

Figure. 8: Geometry of turning process.

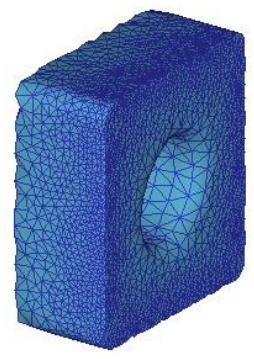

Figure 9: New mesh structure of cutting tool.

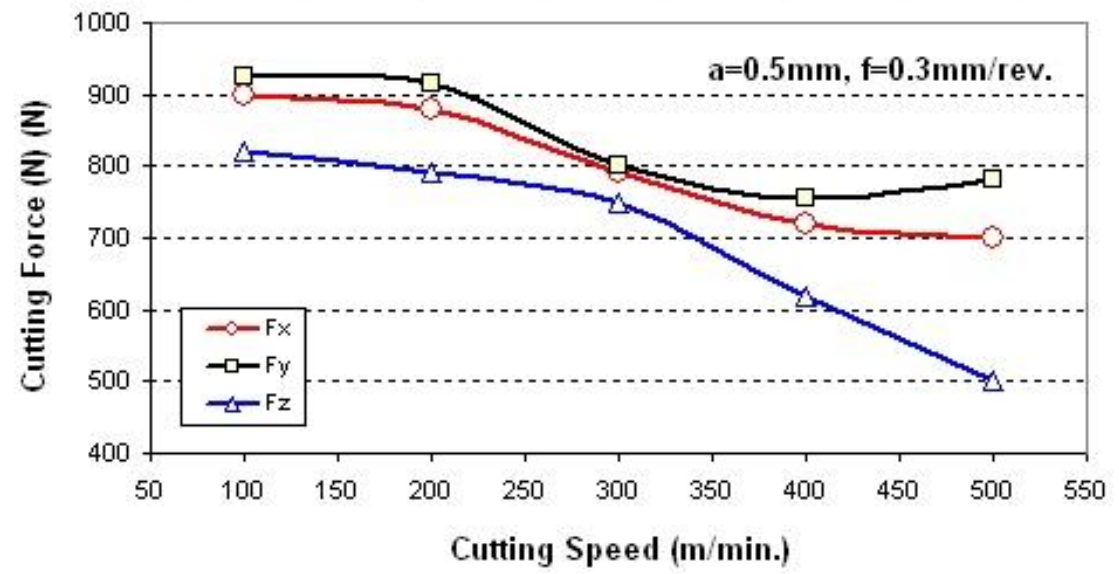

Figure 10: Cutting forces in the five different cutting speeds.

\subsection{Effect to Cutting Tool Stress of Cutting Speed}

One of the factors affecting the cutting performance of the cutting tool are stresses occurred on the cutting tool. To determine stresses occurred on the cutting tool had added a new operation.
Deformation type was selected as isothermal for this operation. As seen in Figure 11, cutting tool was selected as plastic for deformation and fixed from selected faces.

As a result of the analysis, it can be seen 
that temperature in the cutting region increases with increasing cutting speed [11], [12]. Increasing of the temperature will cause the thermal softening in the workpiece. Thus, chip will separate eaiser from the workpiece, and cutting process easier. This reduction in the cutting forces will also cause a reducing in the stress occurred on the cutting tool. This state is seen in the Figure 12 and Figure 13.
Variation in the normal and shear stresses was examined stress results provided from cutting analysis. These stresses are on the rake face and examined up to $1 \mathrm{~mm}$ with $0.1 \mathrm{~mm}$ intervals from cutting edge. Variation in the normal and shear stresses is seen in Figure 14. Provided normal and shear stress distribution is similar to stress distribution of Zorev [14] in Figure 15.

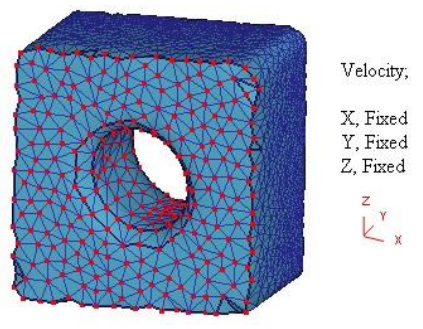

Figure 11: Faces fixed on the cutting tool

\begin{tabular}{|c|c|c|c|c|}
\hline$V=100$ & $V=200$ & $V=300$ & $v=400$ & $v=500$ \\
\hline
\end{tabular}

Figure 12: Stress distributions on the cutting tool in the different cutting speeds

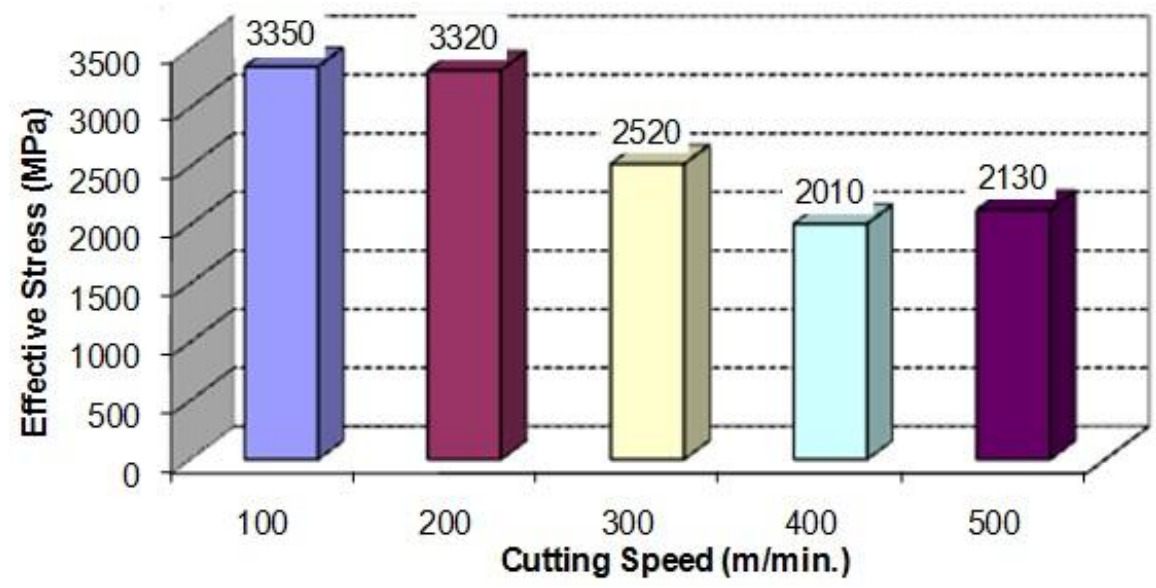

Figure 13: Variation in of cutting force with cutting speed 


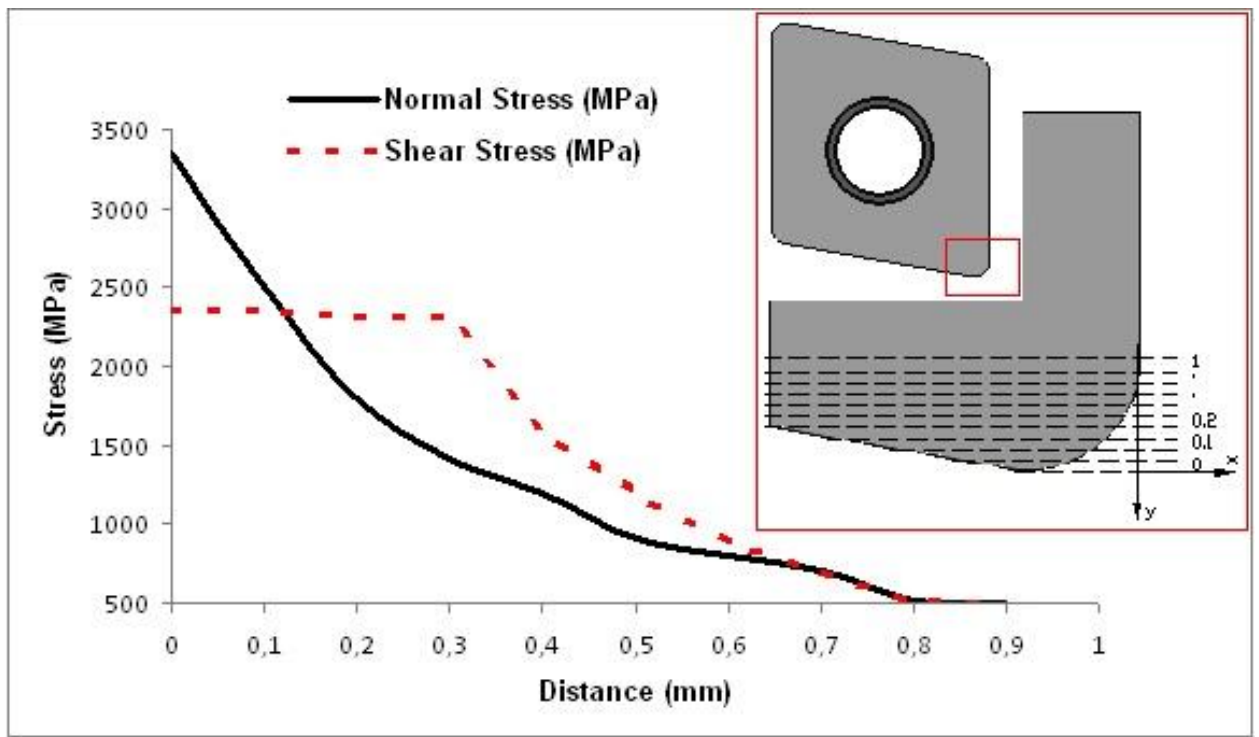

Figure 14: Variation in the normal and shear stress on the rake face

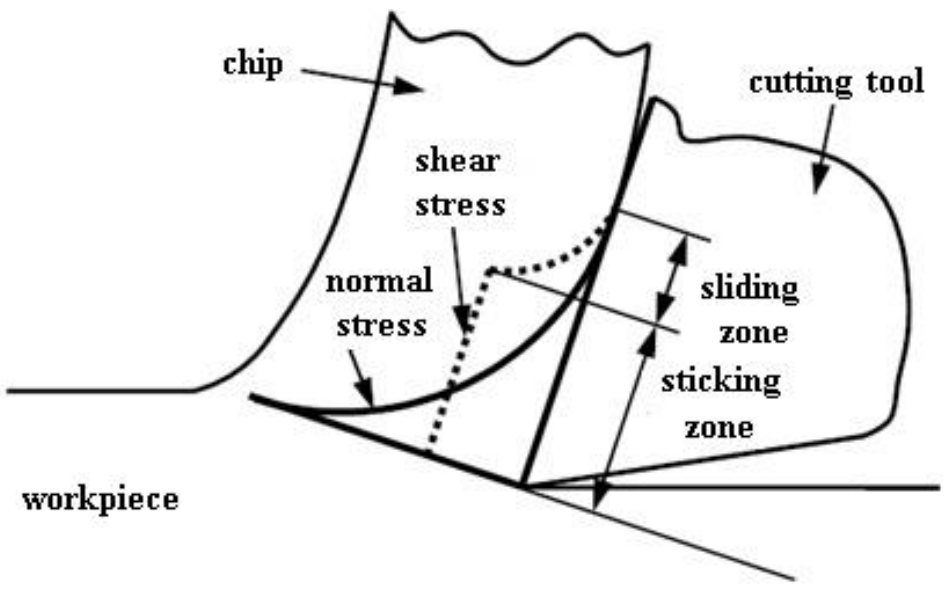

Figure 15: Stress distribution on the rake face of Zorev [14]

\subsection{Effect to Chip Shape of Cutting} Speed

We had said that temperature in the tool-chip interface would increase with cutting speed. Increasing of the temperature will cause the thermal softening in the workpiece. Thus, chip will separate eaiser from the workpiece. As can be see in Figure 16, although continuous chip consists in the low cutting speed, discontinuous chip consists in the high cutting speed.

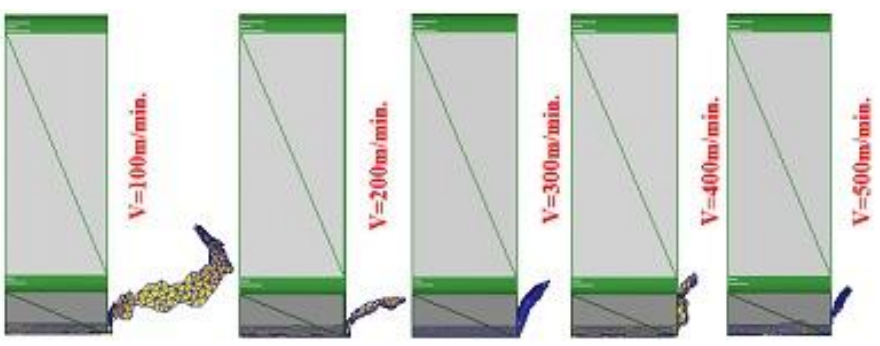

Figure 16: Chip types in the five different cutting speeds 


\section{Conclusion}

In this study, it was researched effects on the cutting force, temperature, tool stress and chip shape of cutting speed;

- It can be said that temperature on the cutting tool increases with increasing cutting speed. Seven different points were selected on the rake face of cutting tool during 0.009 second cutting process. The highest temperature between these points was occurred in the region which around $\mathrm{P} 3$ point. In this region, there is possibility of a crater wear.

- It is observed that a decreasing in the cutting forces with increasing cutting speed. This state is about high temperature occurring toolchip interface in the high cutting speeds. Especially, temperature causes the thermal softening which is higher temperature region according to other regions.

- Decreasing cutting forces will also reason a reducing in the stresses occurring on the cutting tool.

- Variation in the normal and shear stresses occurring on the rake face of cutting tool is similar to stress distribution of Zorev.

- While continuous chip consists of in the low cutting speeds, consists a manner disconnection of chip in the high cutting speeds due to the thermal softening.

\section{References}

[1] A. Duran, M. Nalbant, "Finite Element Analysis of Bending Occurring While Cutting With High Speed Steel Lathe Cutting Tools", Materials and Design, 26, 2005, 549-554.

[2] A. G. Jaharah, S. W. Wahid, C. H. Che, M. Z. Nuawi, N. R. Mohd, "The Effect of Uncoated Carbide Tool
Geometries in Turning AISI 1045

Using Finite Element Analysis", European Journal of Scientific Research, 2, 2009, 271-277.

[3] S. Dechjarern, "3D Finite Element Investigations of the Influence of Tool Rake Angle on Cutting Performance", Asian International Journal of Science and Technology in Production and Manufacturing, 1(2), 2008, 149-158.

[4] H. Yanda, A. G. Jaharah, C. H. Che, "Effect of Rake And Clearance Angles On The Wear of Carbide Cutting Tool", Engineering e-Transaction 4(1), 2009, 7-13.

[5] Bareggi, A.; Donnell, O.; Torrance, A.: Modelling Thermal Effects in Machining By Finite Element Methods, Processing of the 24 th International Manufacturing Conference, 29th-31st August, Waterford 1.1, 2007, 263-272.

[6] İ. Ucun, K. Aslantas, "Numerical simulation of orthogonal machining process using multilayer and singlelayer coated tools", Int J Adv Manuf Technol, 2010, DOI 10.1007/s00170010-3012-9.

[7] G. Patrascu, G. Carutasu, "Using Virtual Manufacturing Simulation in 3D Cutting Forces Prediction", Fascicle of Management and Technological Engineering, Volume VI (XVI), 2007, 1423-1426.

[8] J. M. Zhou, H. Walter, M. Andersson, J. E. Stahl,: "Effect of Chamfer Angle on Wear of PCBN Cutting Tool", International Journal of Machine Tools \& Manufacture, 43, 2003, 301305.

[9] T. Özel, "The Influence of Friction Models on Finite Element Simulations of Machining", International Journal of Machine Tools \& Manufacture, 46, 2006, 518-530. 
[10] B. Li, X. Wang, Y. Hu, C. Li, "Analytical prediction of cutting forces in orthogonal cutting using unequal division shear-zone model", Int J Adv Manuf Technol, 54, 2011, $431-443$.

[11] T. Kitawaga, A. Kubo, "Temperature and wear of Cutting Tools in High Speed Machining of Inconel 718 and Ti-Al-6V-2Sn., Wear, 202, 1997, 142-148.

[12] E. Ng, D. K. Aspinwall, D. Brazil, J. Monaghan, "Modeling of Temperature and Forces When Orthogonally Machining Hardened
Steel", International Journal of Machine Tools \& Manufacture, 39, 1999, 885-903.

[13] J. P. Davim, C. Maranhao, " $A$ Study of Plastic Strain and Plastic Strain Rate in Machining of Steel AISI 1045 Using FEM Analysis" Materials and Desing, 30, 2009, 160-165.

[14] N. N. Zorev, "Inter-relationship between Shear Processes Occurring Along Tool Face and Shear Plane in Metal Cutting", ASME, International Research in Production Engineering, New York, 1963, 42-49. 